\title{
Health, Disease, and Social Structure in Rural India
}

\author{
Devajana Chinnappa Nanjunda ${ }^{1}$ \\ ${ }^{1}$ Social Exclusion Research Centre, Mysore University, Mysore, \\ Karnataka, India
}

J Health Allied Sci ${ }^{\mathrm{NU}}$ 2019;9:22-27

\author{
Address for correspondence D. C. Nanjunda, Social Exclusion \\ Research Centre, Mysore University, Mysore, Karnataka, 570006 India \\ (e-mail: anthroedit@ymail.com).
}

\begin{abstract}
Keywords

- health

- rural

- culture

- social

- illness

Health and disease are the two noteworthy dimensions of behavior. During the lifetime, every individual traverses through health and disease. It is not an all or none type of occurrence but a relative location that explains whether the individual is healthy or unhealthy. The individual perception of health status is largely a psychological phenomenon. In spite of the beginning of the disease process, an individual may not even perceive it at any point of time. An organic disorder may not at all involve an individual until it is perceptible. Conversely, without any organic disorder, an individual may report himself to be unhealthy. Thus, logically, disease and health may coexist in the same individual. These two are not just equally exclusive entities. This study has been performed with two objectives (1) to study the changing social, economical, cultural, political, health, and demographic profile of the studied rural population and (2) to understand the changing illness ideology of the rural people and to find out the existing perception, health-seeking behavior, and culturally bounded attitudes about the onset of certain common diseases, and use of different systems of medicines. This study has been done in the selected districts on 800 households of Karnataka, India, using both qualitative and quantitative techniques.
\end{abstract}

\section{Introduction}

The study of rural health culture is very significant due to various reasons. The study of changing dynamics of medical pluralism and health-seeking behavior among rural people from the medicosociological point of view is very significant because various health problems and practices to cure these are largely influenced by a complex interplay of social, cultural, economical, and political factors. Studying health culture from the sociological point has certain dimensions. The first one is sociology and medicine, which focuses on the contribution of sociological knowledge to the diagnosis and treatment options to cure the disease., Sociology of medicine focuses itself within the sociological study of the medical profession. An in-depth study of health culture of any rural community will help in understanding complete etiology, onset of various discuses/illness, and the healing procedure. ${ }^{1}$

It is found that disease or illness is made of social responses rather than an organic malfunction. Illness or sickness is largely determined by the historical, cultural, social, and geographical context in the rural parts. Also, health behavior sometimes might be of hereditary/customary nature. Sickness behavior will be normally used as a tool to differentiate between diseases as a pathogenic category and illness as a social aspect. Today, rural people are gradually showing significant adoption to the modern medical system for their health issues, and hence the sociologists are closely monitoring these adaptations with respect to the healthseeking behavior and the health care-seeking behavior in a given society. Even though there are several scientific reasons behind the disease and illness, sociology assumes that the society significantly determines sickness as well. In the past, society and culture had some informal criteria to legitimate an illness. This does not hold good today. We feel that sometimes misunderstanding occur regarding the ideology about diseases between the physician and the patients, that is, the patient thinks the disease/illness might have occurred due to folk reasons, whereas doctors opine it is due to some other scientific reasons. Here, rural doctors lack cultural sensitivity. Today, doctors normally consider a disease/illness as legitimate only if it is diagnosed duly by scientific methods. ${ }^{2}$ 
All these factors have vital significance in every rural health culture. The significance will depend on the nature of collectivism adopted for different health cultures. Sometimes, this significance will be linked to the history, origin, and philosophy of a particular health culture that help in shaping his/her behavior with other fellow human beings and the physical world. There are some health cultures that promote separation of individuals from their social and physical environments completely. In this case, the psychosociology process of illness will get much focus. In the same way there are some health cultures that focus health cultures that focus or promote good relationship between an individual and his/her fellow members in the society. In some cases, physiological process of illness will be given low priority. It is often found that the concept of health and illness will be based on the collective surrounding environment, spiritual background, history of the family, and so forth; this has been found true in this study as well. ${ }^{3}$

We found that some of the development activities in the rural areas determine the economic status of the people and finally leads to adopting a new changing sociocultural pattern. This aspect also impacts the health system and health culture of that community. Hence, this issue needs to be studied from the sociological viewpoint. Since the rural society is multicultural, understanding sociocultural and socioeconomic conditions plays a vital role in framing a locally suitable health care module, but this module must be present within their cultural milieu. At the more practical level, scientific study on beliefs and practices will play a vital role in framing culturally acceptable health care interventions for the rural people at their doorsteps. Any study on health culture is very important because (1) there is an interplay of different factors in the onset and healing of certain diseases and (2) it is highly impossible to implant the scores within getting knowledge of peoples' health culture. ${ }^{4}$

Even through different types of medical systems available in the society, choosing of a particular type of medical system is largely governed by the socioeconomic status and gender. In majority of the cases, diagnosis of illness and its seriousness would be crucial factors in selecting a specific therapy. If problems are minor, patients may likely visit a local healer only in rural settings. If it is of multiple syndromes, people would like to visit a biomedical system. Normally, long-standing cultures and beliefs directly or indirectly intertwined with the peculiarities of the illness and health decision depend on social, economic, and cultural factors. In rural areas, in most cases, patient satisfaction and skill of the healer would be very vital in determining any type of health behavior. ${ }^{5}$ However, it is found that no such big variations in using various medical health care facilities with reference to class and caste in the rural areas can be seen because of social mobilizations. It is usually considered that poor people will normally go for traditional healing and well-off people will use modern facilities. ${ }^{6}$

Background of the household head and types of diseases have some vital linking factors in choosing the modern health care system in rural parts. Level of education, occupation, and income of the household head normally will play a vital role here. As we have seen, existence of medical pluralism in a single cultural domain will be a significant factor in rural areas also. It is found that any community will accept a treatment/system when it is of low cost, easily available, and based on the types of diseases where the patient will decide about choosing a better medical system. Before selecting any type of therapy patients will evaluate different medical systems having the above-mentioned features. All these processes give an edge to any disease and relevant treatment as a society-acceptable outcome. After being effectively cured, each patient will narrate his/her own illness experience. Finally, it would be publicly accepted, recognized, and approved. Traditional coated notions of distress also play a vital role in converting a disease into an illness. This will also help in understanding, labeling, and healing a particular type of disease/illness and this is how a health culture gradually constructs/evolves/develops in a society. ${ }^{7}$

It is found that continuous changes in the medical technology, development, etc., will change the attitude of the people toward medical care. It will also affect the health-seeking behavior of a community. Since people often change their attitudes toward medical care, defining health and illness within social life would be a big task. Researching and analyzing sociological study of health and illness now-a-days is very difficult and it is because of the rapid change in the health culture and behavior across societies. Sociology expects that only healthy people will construct a healthy society and will play a vital role in the holistic development of the society. On one hand, medical sociologists feel that efforts should be made to create more awareness about modern health facilities, on the other hand cultural training for formal doctors is the need of the hour. Next, they believe that in a pluralistic health system, private/public/qualified/unqualified systems and personnel need gender-sensitive trainings. Traditional healers should be given at least a basic training in the biomedical health care system. Certain sociologists have also criticized the nature of studies. They have sometimes found research methodology and samples and the political economy of the research process to be questionable. Sometimes, the researchers will be under pressure to give positive or favorable results. Also, funding agencies and government seek to hide real facts. ${ }^{8}$

The socioreligious medical responses to illness in various forms-including the belief and forms will be recognized and get approved over a period of time and build the health culture. As a part of this health culture, members of each community tend to build up a specific belief frame relating to several illnesses/diseases recognized by them. The symptom recognition, assessment, and health decisions associated with the retrieval of health recuperation are predisposed by belief frames connecting to disease caution, multiplication, diagnosis, and cure of each category of diseaserecognized. ${ }^{9}$

Normally, rural folk believe diviners would have special supernatural powers and experience in diagnosing and curing different within a reasonable time. Diviners' extraordinary behavior and knowledge and power will be greatly respected 
such that they find a place in the rural health culture. It is also a normal phenomenon that such persons pass through a phase of experiencing non-ordinary behavioral symptoms. This whole system is methodically connected to stress and strains that the society and culture induce over its members, thus the method of becoming a diviner is also a therapeutic action where a person with inner conflict finds a culturally agreed medium for channelizing his preventions and hostility ${ }^{10}$ Rural concepts of prevention of various health problems and keeping themselves away from the disease-causing elements have become part and parcel of their social life. Lifestyle, food habits, and preventive measures will be in accordance with the local customs, norms, and values. "All these micro-level cognitive cultural information floccus toward broad-based cultural ambiguity, micro level interest, norm configuration, and their intermeshing with the wider political-economic structures of interests to understand even the institutionalized medicocurative systems in their complete societal contexts." ${ }^{11}$ Studies conducted in various parts of villages in India have shown that acts, words, songs chants, worship, and statues suggest and reveal cultural realities other than themselves further natural, supernatural, cosmological, spiritual beliefs that are symbolically and meaningfully ordered. Also, any domain of health culture will have implicit meanings in any health behavior.

Rural people's concept of prevention of various health problems and keeping themselves away from the disease-causing elements has become part and parcel of their inherited health culture. Lifestyle, food habits, and preventive measures will be in accordance with the local customs, norms, and values only. The current study has found that health-seeking behavior of one family may affect the entire village. Lifestyle of a particular person, how seriously he/she considers health problems, and frequency of occurrence of the particular health problem plays a significant role here. Also, beliefs and practices of traditional healers, treatment pattern, and hurdles in accepting modern health care facilities would be significantly vital in shaping common or similar pattern of health-seeking and health-promoting behaviors among the entire rural group. Further, it is found that social, cultural, ecological, political, and physical dimensions shape the health culture of the given rural community. ${ }^{12}$

This study opines that established rural people's health behavior should not be underestimated by citing them as illiterate or superstitious. Even today a major section of the rural people is not ready to accept the modern health system because of their cultural background. Because of resistance, till today many rural-targeted programs have not been successful. It is believed that rural health behavior depends on the particular health culture, geographical area, and the particular ecosystem. Medical anthropologists feel that modern health programs fail to respect peoples' inherited culture, emotions, and spiritual meanings associated with health and disease. Moreover, it is found that the health-seeking behavior of rural people varies according to the type of illness, cause of illness, gender, and age of the person affected by a particular disease and illness. Further, this study has found that poverty, illiteracy, and policy problem are some of the reasons for health inequalities in case of rural people in India. Uneven distribution of modern medical facilities, hospitals, lack of awareness, lack of effective prevention measures, development behavior of certain communities, absence of strong political will, bureaucratic negligence, poor medical infrastructure, malnutrition, transport system, and people's ignorance are some of the hurdles in the way of providing quality delivery of health care service to the rural people that is largely influenced by their socioeconomic and other institutional factors. ${ }^{13}$

This study has revealed that rural populations have suffered from numerous communicable and congenital diseases. Typhoid, malaria, jaundice, cholera, tuberculosis, scabies, and mental illness are highly prevalent. People strongly believe cosmological powers cause disease and illness. Changing socioeconomic process will also influence the pattern of the health culture and health care-seeking behavior. When change happens in the health culture, health-seeking behavior of a particular community will also change. Hence, perception and attitude of the rural community toward different health problems will get a new shape and frame in the due course of time. Finally, it leads to the formation of new health care-seeking behavior when they face such health disorders in the future. When the health culture is strongly influenced by external organics (level of education, migration, media, etc.) in a particular geographical area rural people may develop new health behaviors. This adoption will lead to new health-seeking behavior to resolve health problems within the given ecological setting. This type of forced change in the health behavior of a particular community sometimes will be explicit and sometimes will be implicit. Government and nongovernmental organizations need to look into the cultural fabrics of the rural health for speedy social inclusion before framing any new health policy. ${ }^{9}$

Rural areas in general are marked by poor implementation of health facilities. Government has implemented many rural-specific health programs; however, high concentration of infectious diseases, absence of effective health education, and lack of fundamental facilities are adversely affecting rural people's health. Even today there is no good road facility to many remote villages across the country, and due to this factor new medical technology has not yet reached the villages. Rural people's health today has three important dimensions:

1. Some of the communicable diseases that are most prevalent among the rural people, including malaria, cholera, diarrhea, malnutrition, require good health education, grassroot-level interventions, and a hygienic environment.

2. Some of the noncommunicable diseases, including mental illness and neurological problems, require good medical interventions; also, there is a dearth of some special programs catering to this category of diseases.

3. Focus is also on alcoholism, smoking, and drug addiction.

It is found that the current health culture reflects the norms and values of the wider community within which the household is located and the social and economic possibilities, which in local contexts offer different categorization of households. It seems the community has not understood that 
health culture and health behavior are a social construction. A new paradigm is required that attempts to explain and interpret in the contexts of community and culture that is embedded within normal lives. Health culture is not static, nor is it narrowly prescribed. It is found that each generation reconstructs the structure of patients' experiences and channels health culture to reflect values, social networks, self-esteem, and identity in the society. On the contrary, there are some key features of health culture and behavior that are being reconstructed in the most economically advanced communities as a result of rigorous external interventions. The emergence of the new paradigm, and the extent to which it has universal versus local application, will depend greatly on the approaches, philosophies, and the ideology with respect to health, illness, and medicines. Local culture more or less considers the modern health care as an economic entity, thus ascribing medicines with an economic rather than simply a social value. ${ }^{14}$

Marginalized communities find themselves establishing a separate illness ideology. People's concept about health and illness is sometimes based on their position in the societal hierarchical structure. An interesting aspect found in this study is caste-based illness ideology. People belonging to the higher caste will perform various rituals regularly for seeking a good health status, by spending a considerable amount of money. Illness ideology is quite different in the case of low-caste people. This study also found that low-caste people will strongly believe in cosmology, evil forces, etc., in causing various diseases/illness. However, a notable percentage of them also believe in the scientific theory of illness and disease and deny the traditional belief. This is a good sign also. Low-caste people will perform health-related rituals to the lesser-known gods and deities. Low-caste people will seek help from the priest who belongs to the higher caste to perform the rituals. In the majority of cases, higher-caste priest will not accept this offer. In that case, low-caste people will choose a person among them to conduct the rituals. ${ }^{15}$

Further, it is found that majority of higher-caste people will not participate in any health-related rituals normally organized by the lower-caste people, except in some cases. It shows that higher-caste people are more privileged to have access to services that promote their well-being, whereas lower caste people are more prone to ill health. Even though certain notable percentage of respondents belonging to the lower caste believe in the Western theory of etiology, they perform only rituals to come out of any specific illness/diseases. This study found that illness ideology varies from caste to caste. Caste-based illness ideology studies would be very ideal in this moment.

It is also interesting to find that in a few occasions illness ideology changes from one geographical area to another and from one social context to another. Illness ideology of any community must be studied within the ambit of that social context. It is well established that the role of society in conceptualizing illness and sickness/well-being is normally articulated within the force of different social structures that construct the health culture and health-seeking behavior of a community. It is also found that understanding villager's health behavior and health culture goes beyond the individual body and particular etiology into the context of general culture.

However, the gender perspective of health and illness is also a significant factor in studying the rural health culture. It is evident that understanding social relationships and the degree of personal relationship between the community members is very significant in understanding health behavior and illness ideology in rural areas. People have related different gods, and good and evil forces to different types of illness and diseases. Family also plays a significant role in shaping the illness ideology and health behavior. In majority of the cases, family elders or other family members will play a key role in diagnosing diseases or illness. In some cases, family members only decide in opting the appropriate treatment plan. ${ }^{16}$

Emotional bonds between the patient and his/her family members would be crucial in the case of stress and strain on part of the patient in playing a sick role; the patient's sick role cannot be isolated from his/her social settings and familial circumstances. It is within the social sphere of the family that a disease occurs and its management is resolved; family helps the patient in coping with the stress and difficulties due to the illness. Family relations and obligations sometimes have a major role in influencing the patient to accept the sick role. Also, family only bears the expenditure of the health care of the patient and is recognized legally as the decision-making authority in opting the suitable health care on behalf of the patient.

Studies are required to incorporate vital sociocultural factors in introducing advanced health care system for rural people to know how illness cognitions constructed or health care behavior will be developed over the period of time. There are certain studies to show that how respondents cope up with the existing health deciders. It would be interesting to know how social networks and social support play a role in helping patients to handle the sick role positively, and how cultural differences affect seeking social support. Some cultures will provide social support to patients for certain health problems. However, patients will not show interest in getting that support because of fear of criticism or spreading health issues to others which is an insult or embarrassment. This will discourage the patients in getting social support from the social network. Sometimes, patients may like to have unsolicited support to cope up. In some cultures, patients may not show interest to share true pain with fellow members of the community. They will seek social support from the social network without discussing his/her problems. Studies have also shown that culturally driven social support has a positive impact, and cultural support will help patients to get back to the normal life at the earliest. ${ }^{17}$

The strong belief or faith of respondents on the healing technique does matter a lot. Also, family members, village members, and others play a vital role in opting a particular type of medical assistance within the given context of medical pluralism, including hakims, local traditional healers, nomadic vaidya, Ayurvedic and allopathic doctors. It is found that sometimes medical practice among rural respondents 
will be highly pluralistic in the days to come. Only in certain parts of rural areas both traditional medicine and biomedicine coexist side by side. Government has opened allopathic and Ayurvedic medicine centers in certain rural areas so that rural people can select any type of medical system regarding prevention curative and rehabilitative measures. Hence, we can opine that health-seeking behavior of rural people is gradually becoming flexible today. Experts have opined that there is a dearth of new sociological studies about dynamics of changing rural health culture questioning the philosophy of the system of medicine. The typology of traditional medical practice classified for describing the legal role of traditional medicine in different medical systems is need more indepth study.

Today, in few rural areas (near the city) modern medicinal system dominates. In practice, an exclusive system is pluralistic and an integrated system may include many aspects of traditional medicines. Furthermore, in practice the inclusive and integrated system forms a continuum, just as the exclusive tolerant systems are coterminous with each other. The context of medical pluralism is now being changed because of new socioeconomic, medicalization, globalization, and political development. Accessibility and availability of different medical practices also play a vital role in diffusing health culture and fulfilling health needs of rural people. Due to all these, one day traditional medicinal system may be dislocated from its originality. Emphasizing health behavior issues from the perspective of the rural cultural fabrics toward refusal or acceptance of various medical systems needs a fresh start. Western sociologists say future of traditional medical system is in question because of inclusion of consistent intergenerational contents by the traditional societies.

Rather than any one form of medicine(s), it would be significant if we focus the place of medicine occupied in the everyday life of rural people and it should be studied deeply. Sometimes doing cross-cultural analysis of the practice of different healing techniques and health behavior in different cultures has been found to be very vital in generalizing the pattern of the health culture across the rural society. The psychotherapeutic elements and strong faith on the local healer or vaidya play a highly significant role in curing diseases and sickness. It is found that diviners also are significant in the traditional medical system. As Joshi opined "diviners are the healers who play an intermediate role between the culturally postulated super human and the society." ${ }^{18}$ The healing techniques used by the diviners would be very vital for further sociological study. ${ }^{19-21}$

One patient and multiple health providers such as Ayurvedic, Unani, Sidda, doctors, and herbalists is the current phenomenon today. This pharma health-seeking behavior indicates how medical pluralism is moving (direction) in a given society. The medical system of the society will be normally composed of different medical subsystems found in a cooperative or competitive manner. Usually, complex societies include all types of medical systems in a parallel and sometimes overlapping manner in rural areas. Also, medical pluralism in a society is sometimes based on hierarchical relation, sociopolitical and economical control, etc. However, all these factors sometimes could not interpret the local notion about illness. Sometimes in a pluralistic health care system, the very basic interpretation of illness may get changed over a period of time due to various external factors. Usually, patients do not essentially mind the illness details and the healing approaches as they need immediate cure. "The real issue is that usually sick person and different traditional healers do not consider the underlying medical logics in their treatment."22

Also, it is found that the hierarchical principle of highand low-caste system does not only exist within the social groups. It exists even within medical pluralism. Government will also support modern health care along with other medical systems and traditional medicines. The broad variety of medicinal system coexists alongside traditional medicine in rural societies now. It was established that in some cases the local healer would follow certain diagnostic technique available in modern medicine. As per ICMR reports, people in urban settings are showing interests in Ayurveda and homeopathy rather than allopathy.

Many efforts can be seen in India to incorporate Indian System of Medicine (ISM) into the main stream. It is possible through the use of various social institutions. Drug industry also plays a vital role in creating more networks among them. Also, ISM has psychological and spiritual dimensions. Moreover, we must focus on the efficacy, standardization of medicine, and safety because some types of traditional medicines are not safe to use in the original form. Moreover, it is also found that numbers of trained practitioners are also growing with respect to ISM in India. As Saran (2003) opined, "multiple health seeking" should be recognized and incorporated into a wider coordination across the health system, with better cooperation between public and private providers'. ${ }^{14}$

This study has proved that availability, acceptability, and accessibility of the modern medical care system depend on the community, culture, economy, and political and moral values. If patients get treatment in a government hospital, they will share their experience with a traditional healer. In some cases respondents will seek help from the traditional healers and visit primary health center and in some cases vice versa. Patients may accept the Western medicine or reject it based on their experience in the future. He/she may deny to visit the hospital in the future if he/she is not satisfied with the quality of the service including the duration it took to solve the health problem and other issues. It is not so easy to introduce the Western medicine system in the area where traditional system has existed for a long time. People will normally compare various medical systems available at the door step with respect to quality, history, cost, duration to heal, degree of efficacy, etc. However, all these issues vary from context to context. Rural people always expect medicines should solve their problems as early as possible. They only bother about immediate consequences. Hence, now sociologists are focusing on the phenomenology and political economy that exist with the medical pluralism and the role of social relations in health care management. A perfect 
understanding of medical pluralism in diverse cultural settings is the need of the hour. ${ }^{23}$

\section{Conclusion}

Finally, it can be noted that due to the influence of changing social, economic, and political issues, particular health culture will get framed and reframed continuously over a period of time. To reveal the psycho-sociological compliant of health culture we first need to take into account the overall culture of the community. It is a known fact that certain health culture practices lead to certain health disorders too! Hence, it is very vital to study rural health issues because certain cultural practices by the community will get either by diffusion or THROUGH ANY new local innovations. Social science in general, and sociology in particular, plays a vital role in understanding both qualitative and quantitative changes in various domains of health culture of the rural people. We need empirical studies that come out with new and unique findings and contribute to the theoretical understanding and research domain of the subject more precisely.

\section{Conflict of Interest}

None declared.

\section{References}

1 Lambert H. Helen. Illness, inauspiciousness and modes of healing in Rajasthan, contribution to Indian sociology. New Series 1997;31:253-271

2 Marriott M. Western Medicine in a Village of Northern India, Health, Culture and Community. In: Paul BD, ed. New York, NY: Russell Sage Foundation; 1955

3 Usku AK, Hynie M. Self-construal and concerns elicited by imagined and real health problems. Journal of Applied Social Psychology 2007;37:2156-2189

4 Banerji D. Book Review of the Cultural Frontiers of Health in Village India: A Case Study of North Village by K.A. Hassan. Mumbai, India: Manaktalas;1968

5 Choudhari B. Tribal Health: A Socio-cultural Dimension. New Delhi, India: Inter India Publication;1986

6 Rahman SA. Utilization of Primary Health Care Services in Rural Bangladesh: The Population and Provider Perspectives
[PhD Thesis (unpublished)]. London, UK: London School of Hygiene and Tropical Medicine, University of London;2001

7 Opler ME. The cultural definition of illness in Village India. Hum Organ 1963;2:22-25

8 Albrecht GL. Rationing health care to disabled people. Sociol Health Illn 2011;23:654-677

9 Mishra DN. Rural health care system in India. Rural Integration 1987;6:23-25

10 Ahmed SM. Exploring Health-Seeking Behaviour of Disadvantaged Populations in Rural Bangladesh. Sweden: Karolinska University Press;2000

11 Joshi and Mahajan K. Anthropology and management of health and hygiene: an Indian case study. Joshi PC, and Mahajan A, eds. In: Studies in Medical Anthropology. New Delhi, India: Reliance Publishing House; 1990

12 Mann RS. Concepts of disease and change in Delhi village. Indian J Soc Work 1967;17:353-360

13 Mackian A. Review of Health Seeking Behavior: Problems and Prospects. Manchester, UK: University of Manchester, Health System Development Programme;2003

14 Nettleton SARA. Sociology of Health and Illness. Cambridge, UK: Polity Press; 1995

15 Rahi SC. A study of administration of rural health services in Haryana. Rural Development Journal 1998;12:32-35

16 Orubuloye, IO. Disease, Illness and Society. Ado-Ekiti, Nigeria: Centre for Population and Health Resources;2003

17 Kim J. Trans cultural medicine: a multi-sited ethnography on the scientific-industrial networking of Korean medicine. Med Anthropol 2008;1:31-64

18 Joshi PC. Issues in tribal health and medicine. Kalla and Joshi PC, eds. In: Emerging Issues in Tribal Health and Medicine. New Delhi, India: Reliance Publishing House; 1990

19 Chouby H. Changing health culture among rural people. Soc Action 2000;2:34-36

20 Gupta GR. Mein Currents in Indian Sciology-The Social and Cultural Context of Medicine in India. New Delhi, India: Vikas Publishing House; 1996

21 Sharma U. Using Complimentary Therapies: A Challenge to Biomedical Hegemony? In: Williams SJ and Calnan M, eds. Modern Medicine: Lay Perspectives and Experiences. London, UK: UCL Press; 1996

22 Salvador A, Costa R. Coping with competition: neuroendocrine responses and cognitive variables. Neurosci Biobehav Rev 2009;33(2):160-170

23 Duggal R. Health care utilisation in India. Health Millions 1994;2(1):10-12 